\title{
Macro-anatomy of the Bones of Thoracic Limb in Dalmatian Pelican (Pelecanus crispus)
}

\section{-Author(s)}

Ilgün $R^{\prime} \quad$ (DD https://orcid.org/0000-0003-0150-3008

Aksaray University, Faculty of Veterinary Medicine, Department of Anatomy, 68100, Aksaray/Turkey.

\section{a Mail Address}

Corresponding author e-mail address Ramazan Ilgün

Aksaray University, Faculty of Veterinary Medicine, Department of Anatomy,

68100, Aksaray/Turkey.

Phone: +903822882863

Email: rilgun1980@hotmail.com

\section{ABSTRACT}

In this study, the bones forming the poultry skeleton of the Dalmatian pelican were macroscopically examined. For this purpose, three Dalmatian pelicans were used. In the Dalmatian pelicans, the shoulder girdle (Ossa cinguli membri thoracici) is formed by the scapula, os coracoideum and clavicula bones. The scapula bone was short and flat. The humerus was a long bone with a cylindrical, pneumatic structure. Os corocoideum was also in the processus coracoideus tuber. Radius formed a joint with the ulna, and presented a slight slope from proximal to distal direction. Ossa carpi bones (skeleton manus) were composed of os carpi ulnare and os carpi radiale. The phalanx proximalis digiti majoris had a triangular shape on the dorsal side and two blade-shaped phalanxes. The bones that make up the structure of the Dalmatian pelican's wing have significant similarities to other birds, but also to have many particular characteristics.

\section{INTRODUCTION}

The Dalmatian pelican (Pelecanus crispus), which lives in wetlands, ponds and reeds, belongs to the Pelecanidae family according to the scientific classification. It is called Dalmatian pelican because of its curved and raised hair on its skull. It can be distinguished from the white pelican because of its large structure and its long beak. The habitat of Dalmatian pelicans in Turkey is the inner waters, ponds and reeds (Demirsoy, 2003, Trakus, 2017).

In the taxonomy of birds, the skeleton of poultry has distinguishing characteristics (Demirsoy, 2003). In birds, the wing is connected with the shoulder girdle (cingulum membri thoracici), which structure is composed by the scapula, os coracoideus and furcula (Bahadır, 2002). Ossa alae, the free part of the wing; consists of humerus, ulna, radius, carpometacarpus and ossa digitorum manus bones (Feduccia, 1975, Nickel et al., 1977, Chiasson, 1984, McLelland, 1990, Baumel et al., 1993, Lök \& Yalçin, 2007). In chickens, quails and domestic ducks, the humerus is longer than the antebrachium, whereas in pigeons, the antebrachium is longer than the humerus (Yıldız et al., 1998). Many bones of the poultry skeleton have pneumatic structure (Feduccia, 1975; Nickel et al., 1977; Bahadır, 2002; Lök \& Yalcin, 2007). The olecranon part of the ulna, which is one of the antebrachium bones in the poultry, is weakly formed (Doğuer \& Erençin, 1964; Bahadır, 2002). The metacarpus is called carpometacarpus because of the ossa carpi bones are fused with the metacarpus in birds (Chiasson, 1984; McLelland, 1990; Bahadır, 2002). Poultry have three ossa digitorum manus (Feduccia, 1975; Nickel et al., 1977, Bahadır, 2002, Lök \& Yalçın, 2007). 
Studies on the wing bones of chickens, domestic ducks, pigeons, quails (Yıldız et al., 1998), rock partridge, pheasant (Lök \& Yalçın, 2007), domestic goose (Bahadır et al., 1993) are published in literature. However, in Anatolia, to the best of our knowledge, there are no scientific studies on the wing bones of waterfowl, such as the Dalmatian pelican. However, studies on the macroanatomical structure of the Dalmatian pelican may aid the research on the flying and wing structure of waterfowl.

The aim of this study was to contribute to the body of knowledge by examining the macro-anatomical features of the bones forming the skeleton of the front limb of the Dalmatian pelican.

\section{MATERIALS AND METHOD}

Between 2014 and 2016, the bones of three dead adult female hill pelican found in ponds and reed beds of the Aksaray region brought to the Aksaray University Veterinary Faculty Research and Diagnosis laboratory by villagers were examined.

The bones were boiled in water containing 10\% $\mathrm{NaHCO}_{3}$ for 3 hours, and then macerated in $\mathrm{H}_{2} \mathrm{O}_{2}$ water for 3-5 minutes (Evans, 1974; Tasbas \& Tecirlioglu, 1996). The anatomical structures of the wing bones were photographed with a camera (Canon CE500, Japan). The Nomina Anatomica Avium was used as the basis for writing the terminological statements (Baumel et al., 1993).

\section{RESULTS}

In Dalmatian pelicans, the shoulder girdle (ossa cinguli membrithoracici) consisted of the scapula, os coracoideum, clavicula and sternum bones.

\section{Scapula}

The Dalmatian pelican scapula bone was short and flat shaped. In caput scapulae, the acromion was cranially curled. The tuberculum coracoideum was spherical. The processus glenoidalis scapulae facies articularis humeralis part was superficial. The collum was curved towards scapulae ventral. The corpus scapulae was inclined towards the caudal cylinder. The tuberculum $\mathrm{m}$. scapulotricipitis was in the form of a rough ridge (Figure 1.A).

\section{Os coracoideum}

In the dorsal part of the os coracoideum, the processus acrocoracoideus was in the form of lump from extremitas omalis coracoidei. Impressio lig. acrocoracohumeralis was depressed. Proc. glenoidalis coracoidei and facies articularis humeralis were visible.The facies articularis scapularis was narrow, and the cotyla were concave. Proc. coracoideus was medially located. Corpus coracoidei section foramen n. supracoracodei was prominent. Proc. lateralis was sharp at the extremitas sternalis coracoidei part. Angulus medialis was sharp, facies articularis sternalis was visible (Figure 1.B).

\section{Clavicula (Furcula)}

The furculae bones formed the clavicle bell extending right to left in a flat " $\mathrm{V}$ " shape. The proc acromialis claviculae in extremitas omalis claviculae was present in the dorsal region of the clavicula. The facies articularis acrocoracoidea was concave and presented a rough surface. The extremitas sternalis coracoidei were formed by the apophysis furculae joining with sternum's apex carinae in the form of a ball (Figure1.C).

\section{Sternum}

The sternum in the ventral part of the chest was shaped as a flat boat. The carina sterni consisted of corpus sterni parts. Carina sterni was flat, wide and concave. It was the ventral part of the sternum. The apex carinae merged with the furculae in a pointed protrusion. The facies lateralis presented a flat surface carinae and distinctive linea intermuscularees. The crista lateralis carinae on the margo cranialis carinae was slightly protruding and the pila carinae was slightly relieved. The surface of facies muscularis sterni on the corpus sterni was rough. The spina externi rostri, which forms the rostrum sterni, was triangle-shaped, and the margo caudalis sterni presented a sharp notch structure with incisura lateralis (Figure 1.C).

\section{Ossa Alae (Membri thoracici)}

The wing bones (ossa alae) of Dalmatian pelicans are composed of skeleton brachii (humerus), skeleton antebrachii (ulna and radius), skeleton manus (ossa carpi, carpometacarpus, ossa digitorum manus).

\section{Skeleton brachii (Humerus)}

The Dalmatian pelican humerus was a long bone with a cylindrical, pneumatic structure. Dorsally, the caput was egg-shaped and slightly medial-facing, and exceeded the humeral tuberculum dorsal alignment. The incisura capitis humeri caput was located between the humerus and the tuberculum ventrale as a thin notch. The impressio coracobrachialis caput was shallow in the cranioventral of the humeri. 


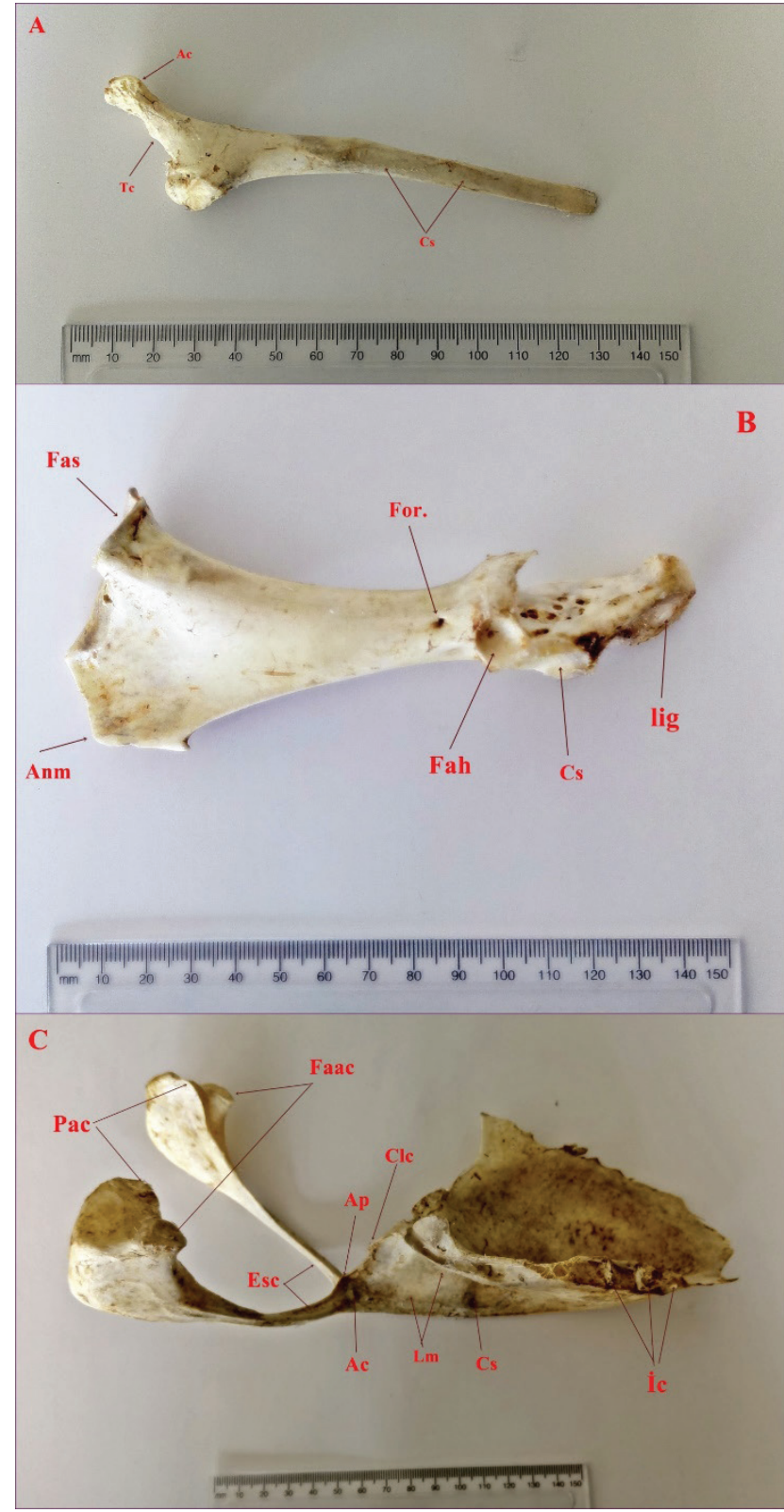

Figure 1 -A) Dorsal view of the Pelecanus crispus scapulae. Ac. Acromion, Tc. Tuberculum coracoideum, Cs. Corpus scapulae. B) Dorsal view of the Pelecanus crispus os coracoideum. Fas. Facies articularis sapularis, Anm:Angulus medialis, For: Foramen $\mathrm{n}$. supracoracoidea, Fah: Facies articularis humeralis, Cs: Cotyla scapularis, Lig: Impressio lig. acrocoracohumeralis. C) Dorsal view of the Pelecanus crispus furcula and sternum. Pac. Proc.acromialis claviculae, Faac. Facies articularis acrocoracoidea, Esc. Extremitas sternalis coracoidei, Ap. Apophysis furculae, Clc. Crista lateralis carinae, Ac. Apex carinae, Ic. Incisura intercostalis, Lm. Linea intermusculare, Cs. Carina sterni.

In the proximomedial of the humerus, the crista deltopectoralis was slightly and cranially bent. The fossa pneumotricipitalis was located deeply in the proximodorsal part of the humerus and contained 2-3 foramen pneumaticum. At the distal part of the humerus, the incisura intercondylaris separated the condylus ventralis humeri and condylus dorsalis humeri by a deep notch. The fossa olecrani was a deep pit, while the fossa $\mathrm{m}$. brachialis was shallow (Figure 2).

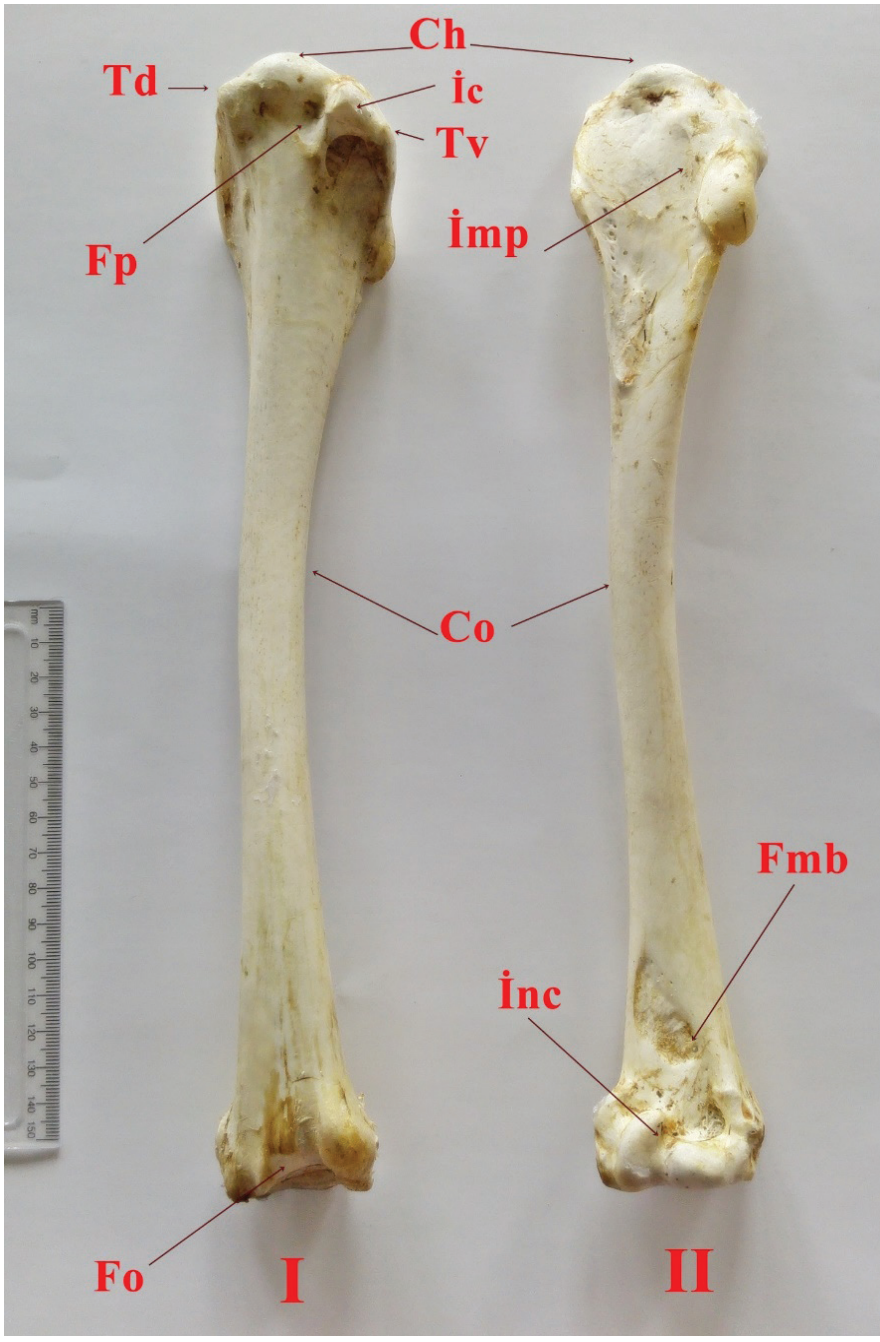

Figure 2 - I. Caudal view of the Pelecanus crispus humerus. Td. Tuberculum dorsale, Fp. Fossa pneumotricipitalis, Ch. Caput humeri, Co. Corpus humeri, Ic. Incisura capitis, Tv. Tuberculum ventrale,Fo. Fossa olecrani. II. Cranial view of the Pelecanus crispus humerus. Imp.Impressio coracobrachialis, Inc. Incisura intercondylaris, Fmb. Fossa m.brachialis,

\section{Skeleton antebrachii (UIna and Radius)}

The antebrachii bone was the longest bone of the wing. Radius and ulna were bones. From these bones the ulna was shaped long and thick. The radius was thin and cylindrical.

\section{Ulna}

The ulna was a pneumatic bone that decreased in thickness from proximal to distal direction. In the extremitas proximalis ulnae, distinctive cotyledons and cotylaventralis joint pits were present. The impressio $\mathrm{m}$. brachialis under the cotylaventralis was in a deep subsidence position. In the proximal ulna, proc.cotylaris was located as a flat bulge in the dorsalis cranial part. The olecranon protrusion was point-shaped. The impression scapulotricipitis was deep along the margocaudalis, there was a large number of remigales ventrales extending from the proximal to the distal 
part of the corpus ulnae, papillae remigales caudales towards caudal part, and several papillae remigales ventrales towards ventral part. The distal part of the depressio radialis was detected in the prominent position (Figure 3).

\section{Radius}

The radius formed a joint with a slight inclination towards the distal portion from the proximal portion with ulna. In the caput radii, the cotylahumeralis formation was mildly depressed. The tuberculum bicipitale radii was detected as a flat protrusion. The lines of the linea intermusculares along the corpus radii were faint. The sulcus tendinous was a shallow depression in the distal part of radius (Figure 3 ).

\section{Skeleton manus (Ossa carpi)}

The wrist bones (skeleton manus) consisted of os carpi ulnar and os carpi radiale. The pecten part of the wing carpometacarpus bones form three bones as os metacarpalealulare, os metacarpale majus and os metacarpale minus. Dorsally, the os metacarpalealulare joined with the os metacarpale majus and the osmetacarpale minus. The os metacarpale majus and os metacarpale minus were joined at the proximal and distal sides, forming an opening. The os metacarpale

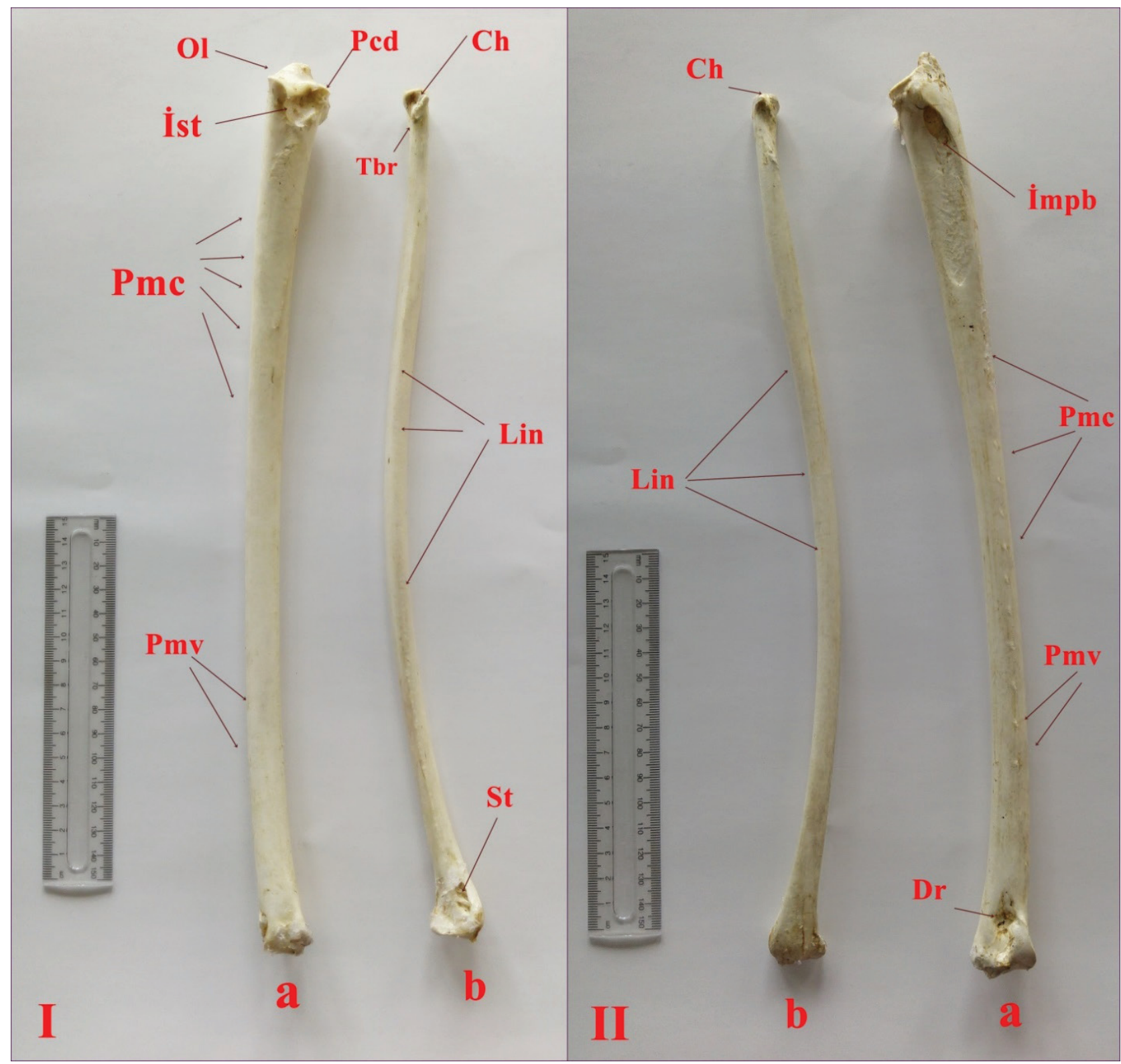

Figure 3 - I. a)Dorsal view of the Pelecanus crispus ulna. Ol. Olecranon, İst. İmpressio m.scapulotricipitis, Pcd. Proc.cotylaris dorsalis, Pmc. Papillae remigales caudales, Pmv. Papillae remigales ventrales. b). Dorsal view of the Pelecanus crispus radius. Ch.Cotylahumeralis, Tbr. Tuberculum bicipitale radii, Lin. Linea intermusculares, St. Sulcus tendinosus. II. a)Ventral view of the Pelecanus crispus Ulna. Impb. Impressio m. brachialis, Dr. Depressio radialis. b) Ventral view of the Pelecanus crispus radius.Ch.Cotylahumeralis, Lin. Linea intermusculares. 
allure in the dorsal part of the proc. extensorius, ventral part of the proc. the alularis protrusion was prominent (Figure 4).

\section{Ossa digitorum manus}

It was composed of three bones: phalanx digiti alulae, phalanx proximalis digiti majoris and phalanx distalis digiti minoris. The phalanx proximalis digiti majoris consisted of two phalanx, which dorsal part was triangular, and the ventral part was blade-shaped. In the middle of the dorsal phalanx, the pila cranialis protrusion extended ventrally (Figure 4).

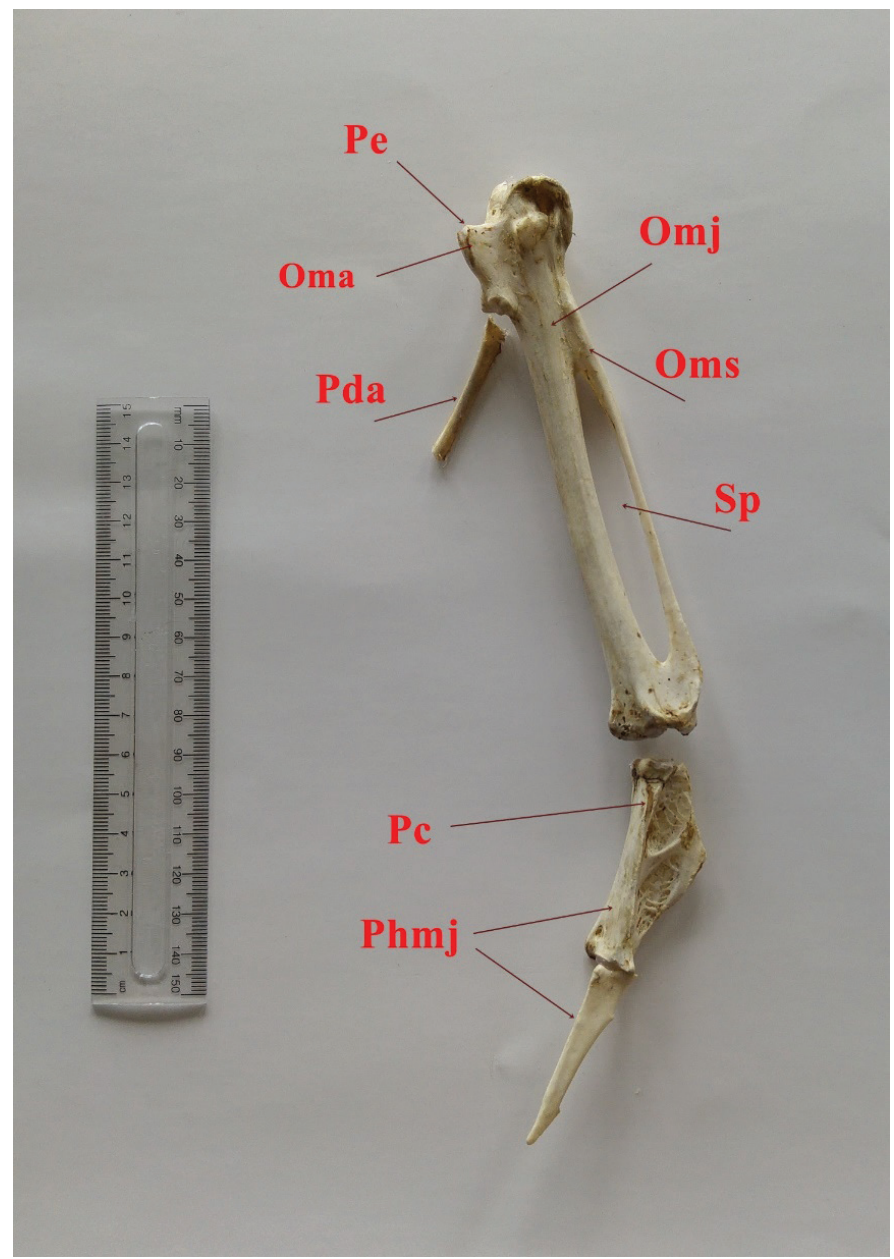

Figure 4 - Carpal and metacarpal bones, and phalanges of the Pelecanus crispus. Pe. Proc.extensorius, Oma. Os metacarpalealulare, Pda. Phalanx dig.alulae, Omj. Os metacarpalemajus, Oms. Os metacarpale minus, Sp. Spatium intermetacarpale, Pc. Pila cranialis, Phmj. Phalanges dig.majoris.

\section{DISCUSSION}

Bahadır (2002) reported that the wing is connected with the shoulder girdle (Cingulum membri thoracici) and the free part of the wing forms the ossa alae bones in birds, observed in the Dalmatian pelican in the present study.
The bird anatomy books by Feduccia (1975), Nickel et al. (1977), McLelland (1990), and the studies of Cubo \& Casinos (2000) in pheasants, Bahadır (2002) in ducks, and Lök \& Yalçın (2007) in partridges reported that the humeral bones in the pheasants and partridges have pneumatic structure. The pneumatic structure was also observed in the bones examined in this study.

In poultry, McLelland (1990) reported that the scapula is sharp-edged, whereas Bahadır (2002) reported as a flat, narrow, sword-like long bone in birds. The Dalmatian pelican scapulae bone was short and flat.

Bahadır (2002) stated that the two bones on the right clavicula and left clavicula form the individual bones named furcula and furcula that resemble the letter " $\mathrm{V}$ ". This was also observed in the Dalmatian pelican.

Nickel et al. (1977) described that in ducks and geese, the sternum is dorsally concave in and ventrally convex, while Dyce et al. (1996) reported that the sternum is narrow and long in chickens. In addition, Sathyamoorthy et al. (2012) reported that, in gray pelicans, the sternum presented a caudal to cranial ventricular boat-shaped depression.

Demirkan (2002) observed in ducks, that the foramen nutriciumis present in the corpushumeri, as well as Bozkurt et al. (2002) in bald-headed ibis and Lök \& Yalçın (2007) in partridges and pheasants. The foramen nutricium was not apparent in Dalmatian pelicans.

Baumel et al. (1993) reported that the foramen pneumaticum was not present in the humerus of penguins, cormorants and many duck species, while Lök \& Yalçın (2007) observed its in the humerus of partridges and pheasants. In the present study, the foramen pneumaticum was detected in Dalmatian pelicans.

According to Baumel et al. (1993), the impressio coracobrachialis is located at different depths in many species of poultry, which was also observed by Lök \& Yalçın (2007) in partridges and pheasants. In our research material, the Dalmatian pelicans, a shallow impressio coracobrachialis caput was detected in the cranioventral part of the humerus.

Several authors (Demirkan, 2002; Bozkurt et al., 2002; Lök \& Yalçın, 2007) stated that, in poultry, the antebrachium is thicker and longer than the radius. Also, Bahadır (2002) reported that they are almost equal in length to the birds. In our study, the ulna was thicker and longer than the radius. 
Lök \& Yalçın (2007) showed that in partridges and pheasants, the impressiom. scapulotricipitis is present as a shallow depression near the prominence of the proc. cotylaris dorsalis the ulna. The examined Dalmatian pelicans also presented similar structures, but the impressiom. scapulotricipitis was deep.

Bozkurt et al. (2002) reported that in the corpus ulnae, there are caudal papillae remigalescaudales extending from the proximal to the distal direction, as well as double, serrated structures named papillae remigales ventrales towards the ventral direction, which were also observed by Lök \& Yalçın (2007) in partridges and pheasants. This formation was clearly seen in Dalmatian pelicans.

Lök \& Yalçın (2007) reported that the radius of pheasants ventrally curves, and that in partridges it starts perpendicularly and slightly twits in the ventral direction. The radius of the Dalmatian pelicans also curved, similarly to that of pheasants.

Literature reports (Feduccia, 1975; Nickel et al., 1977; Mc lelland, 1990; Baumel et al., 1993; Bozkurt et al., 2002; Bahadır, 2002; Demirkan, 2002; Lök \& Yalçın, 2007) observed that ossa digitorum manus was composed of three bones in poultry, which was also determined in the present study.

Considering that Dalmatian pelicans are waterfowl, the bones of the ossa membri thoracici of Dalmatian pelicans were examined in detail. It was determined that, despite some differences, Dalmatian pelicans present important osteological similarities with gray pelicans, chickens, quails, ducks, rock partridges, pheasants, long-legged buzzards (Buteo rufinus) and cormorants.

\section{REFERENCES}

Bahadır A. Evcil kuşların anatomisi (Hareket Sistemi). Ankara: Medisan Yayınları; 2002

Baumel JJ, King AS, Breazile JE, Evans HE, Vanden Berge JC. Nomina anatomica avium. Cambridge: Nuttall Ornihological Club; 1993.
Bozkurt EU, Düzler A, Ozgel,O, Kurtul I. Morphometric and morphological features of the bones of the wing in bald ibis. Indian Veterinary Journal 2002;79:470-476

Chiasson RB. Laboratory anatomy of the pigeon. Dubuque: WMC Brown Company Publishes; 1984.

Cubo J, Casinos FLS. Incidence and mechanical significance of pneumatization in the long bones of birds. Zoological Journal of Linnean Society 2000;30:499-510.

Demirkan AÇ. Ördekte iskelet sistemi. Ankara: Üniversitesi Sağlık Bilimleri; 2002.

Demirsoy A. Yaşamın temel kuralları. omurgalılar/amniyota (sürüngenler, kuşlar ve memeliler). MeteksanYayınevi 2003;(3):230-278.

Doğuer S, Erençin Z. Comparative anatomy of domestic birds, Ankara: Ankara Veterinary Medicine Publishing; 1964.

Dyce KM, Sack WO, Wensing CJG. Text book of veterinary anatomy. Philadelphia: W.B. Saunders Company; 1996. p.813-837.

Evans HE. Guide to the dissection of the budgeriar and chicken. Columbia: School of Veterinary Medicine, University of Missouri; 1974. p.9-12.

Feduccia A. Sisson and Grosman's the anatomy of the domestic animals. In Getty R, editor. Aves osteology. Philadelphia: WB Saunders Company; 1975. p.1790-1802

Lök,S, Yalçın H. The Comparative macroanatomic researches on bones of wing (ossea alae) in rock partridges ( $A$. graeca) and pheasants ( $P$. colchicus). Veteriner Bilimleri Dergisi 2007;21(2):85-94.

McLelland J. A color atlas of avian anatomy. London: Wolfe Publishing;1990. p.45-53.

Nickel R, Schummer A, Seiferle E. Anatomy of the domestic birds. Berlin: Verlag Paul Parey; 1977. p.3-25.

Taşbaş M, Tecirlioğlu S. Maserasyon tekniği üzerinde araştırmalar. Veterinary Journal of Ankara University 1996;12(4):324-330.

Trakus. Türkiye'nin anonym kuşları. Kuş türleri; 2017 [Erişimt arihi, 05]. Available from: www.trakus.org.

Sathyamoorthy OR, Thirumurugan R, Senthil Kumar K, Jayathangaraj MG. Gross anatomical Studies on the Sternum and Clavicle of Spotbilled Pelican (Pelecanus philippensis). Tamilnadu Journal of Veterinary, Animal Science 2012;8(3):166-170.

Yıldız H, Yıldız B, Eren, G. Tavuk, yerliördek, güvercin vebıldırcınlarda humerus ile antebrachium kemikleri üzerine morfometrik araştırma. Uludag University Journal Faculty of Veterinary Medicine 1998;17(3):87.91. 